\title{
Study on the Construction of Student Team-Type Associations under the College System in Universities
}

\author{
Hairui Sui ${ }^{1, *}$, Fanglin Xie ${ }^{2}$ \\ ${ }^{1}$ School of Automotive Engineering, Harbin Institute of Technology (Weihai) \\ ${ }^{2}$ Department of Student Affairs, Harbin Institute of Technology (Weihai) \\ Weihai, Shandong, China \\ E-mail: hitsnaoe@163.com
}

\begin{abstract}
More and more universities begin to explore the new mode of students' education and training through the establishment of residential college system. The student association is an important part of the construction of college system in universities. It is not a simple transition from a school or department to a college, but how to build a team-type association under the college system. This paper analyzes the current situation of the development of the college at home and abroad and the puzzlement of the development of the student association. For the sustainability and the educational function of students' associations, we put forward the idea of building a team-type association based on the four dimensions of goal identity, emotional identity, management identity and value identity under the college system.
\end{abstract}

Keywords—college system; construction; team-type associations; identity

\section{THE DEFINITION OF THE COLLEGE SYSTEM.}

\section{A. The comparison between the Chinese and foreign college system.}

In ancient China, the first official college opened in the Tang Dynasty and got development in the Song Dynasty, Yuan Dynasty and Ming and Qing dynasties. At the same time, there were alternate changes between the prosperous period and the declining period. The college is a place for private or official students to teach and study knowledge. In modern times, the new-style schools set up throughout the country replaced the original educational methods of the college system. As a long-standing tradition of education, English residential college education is neither England initiating nor exclusive. It is a fusion of liberal education philosophy, residential college system, the classic courses and site spirit which all constitute the educational pattern. This kind of educational mode carried the best forward at Oxford and Cambridge University later, so we called it English residential college tradition [1]. Then the residential college system was gradually adopted by the higher education institutions in Europe and the United States. It could give the students in the college the space to study consciously, and also the efficient management mode. The higher education managers could learn from this mode in the cultivation of innovative awareness. The residential college system is a widely used educational management model in Europe and
America, and it is also an important carrier for the cultivation of talents in higher education.

\section{B. The characteristics of the development of the college system in China}

According to the reality of the development of the college system in higher education in China, and the research achievements of researchers both at home and abroad in the college system, the college system should combine general education with professional education, encourage college students with different backgrounds to communicate with each other, and at the same time meet the requirements of students' self-personality development, and finally let the students get the all-round development education management mode. Dr. He Yi's book A Study of College System in the Contemporary University Institution explores the origin of modern university academies, and constructs the construction path of modern university academies from the meso-level of general education system, professional education system, internal governance mechanism, student guidance and development [2].

The College system can effectively break the traditional system of accommodation, so that the students of universities could achieve random mixed accommodation. At the same time, students of different grades or majors can learn from each other, integrate with each other in culture and improve their social communication ability. The academic counselor lives and study in the student apartment. These mentors can not only exchange knowledge with students during class, but also carry out academic research and exchange views with students in the apartment. The communication or perplexity of the students in the apartment can be solved immediately, so they can guide the students to develop their own professional knowledge of learning.

The general education under the college system sets up a large number of courses which are not professional in nature and do not have the character of fame and interest, which are used to cultivate those who have physical and mental health, have a sense of social responsibility, and develop in an all-round way. College system is a good way to carry out general education in universities, which can effectively achieve the goal of cultivating talents with innovative spirit. The college system can break through the limitations of different 
majors and create favorable conditions for students majoring in different majors to exchange and study with each other. The college provides leisure extracurricular activities for students, creates a good atmosphere for students to learn cultural knowledge and appropriate professional knowledge exchange environment, and gradually condenses the spiritual and cultural connotation of the college. Under the management mode of the college system, we should cultivate students' sense of honor and identity, foster the formation of their good character and good behavior habits, and inject new vitality into the inheritance and innovation of campus culture.

\section{THE CHARACTERISTICS OF THE DEVELOPMENT OF STUDENT ASSOCIATIONS}

The student association refers to the mass student organizations which, in order to realize the common will of members and meet the needs of individual interests, are formed voluntarily according to their articles of association. The student association is an important carrier of campus culture construction in China and the leader of the second classroom in Chinese universities[3]. Under the background of deepening the comprehensive reform of higher education in China, the college system is becoming more and more important for students' learning style and life style reform. The student associations under the College system are equivalent to the organization of students which makes use of some behaviors and cultural activities in their daily life to form a special psychological state of life, learning and culture. Students' colleges with students' apartments as the center include restaurants for meals, places for cultural activities, and service sites of a commercial nature, which gather together the aspects of learning, life and communication, and rest. Compared with previous student apartments, the colleges are more space-rich and functionally more diverse. Students begin to enter active participation from passive management, and the limitations of the traditional students' resting space are broken. The college becomes a further extension of the classroom, creates a platform for different students to exchange different ideas, emotional communication, information obtaining and personality perfection.

With the development of campus students' associations, students' ideological and political education must be integrated into the activities of students' associations. By setting up its own committee, the organization functions of each association should be improved to a certain extent. The professional construction of student associations should be greatly promoted so as to improve the quality of the development of students' associations. Let the cultural activities of the association be more innovative, targeted and forward-looking so that the operation of these associations can be more specialized and refined. The guidance teachers of student associations in universities should not only guide and manage the development of association activities, but also cultivate students' good sense of responsibility. If the student association without the guidance of the relevant teachers, its cultural quality is difficult to improve more rapidly. Abundant resources are one of the necessary conditions for the sustainable development of community[4]. In a certain period of time, there are certain restrictions on the use of resources within the school, and there are more resources in the society.
Student associations should be based on schools and at the same time face the whole society. It is very important to establish a long-term cooperative relationship with the enterprises or industry associations where the university is located, and fully tap the support of alumni so as to realize the sharing of resources in talent, economy and technology.

\section{THE CONSTRUCTION STRATEGY OF TEAM-TYPE ASSOCIATION BASED ON THE COLLEGE SYSTEM}

\section{A. The goal identity of the team-type association}

As a college student association, it must have a clear goal. We can clearly find that most student associations gradually enter into a stagnant state after running for a period of time. The important factor here is that there are problems to be solved in the construction of the association's goal, which may be that the goal is not clear or reasonable enough. It can bring a lot of difficult to deal with in the process of development. The student association with team spirit has more advantages than the general student association in the construction of the goal. Once a member of an ordinary association has the initiative to unite and cooperate with each other in order to achieve team goal, he can devote a lot of passion and enthusiasm on many activities of the student association. In this way, it is possible to use the shortest time, output to maximize the effect. The waste of resources and time will gradually decrease in the activities so that the effectiveness of the activities of student associations has been significantly improved. The college can rely on professional associations to carry out systematic, scientific, and standardized social and professional practice activities in the second classroom, so as to promote young students to combine professional knowledge learning with practical ability training, and to receive education in the process of serving the people, to increase talent in the practice of dedicating society[5].

\section{B. The emotional identity of the team-type association}

A student association is a bond of emotion, a voluntary formation of students on the basis of their mutual identity. Members speak freely to each other, express what they think and act so that they can be encouraged and supported by each other. It can make unhealthy psychology such as inferiority and irritability, depression and anxiety; paranoid hostility and so on gradually vanish. The harmony created by the association activities and the advancing group psychological atmosphere can make students in a kind of positive influence. It can make their spiritual world richer, healthier, and alleviate the psychological pressure of students to the maximum extent.

The team-type association can help its members find more sense of belonging and identity. The students' association with team spirit has the same goal. In the aspect of psychology, the members of each group can support each other and be aware of the existence of others. They act on each other in terms of behavior and have an influence on each other. In this situation, the psychological situation of the group can have a more direct impact on the behavior of each person and the purpose of the association. Therefore, it can also make up for the bad effect caused by the incompact structure of the students' associations. 


\section{The management identity of the team-type association}

In order to ensure the realization of its long-term goal and the efficiency of its own operation, standardized management is an indispensable guarantee for any student association. First of all, establish a perfect management system and standard work system; make clear the work focus of each stage of the student association, which can ensure the smooth transition of each work and the good inheritance of the associated culture during the transition of the student association. Secondly, in order to ensure the institutionalization of student associations and the effectiveness of standardized management, we should pay special attention to the necessity, scientific standardization, fairness and rationality of the system and the seriousness of the implementation of the system. Thirdly, with the acceleration of social change, the institutionalized management of student organization should pay attention to student-oriented, mobilize students' enthusiasm and creativity, and tap their potential.

The generality of the membership is a very special feature for the students' associations. Many student associations have no strict restrictions on joining and leaving their organizations, and they are relatively loose in management. This will make the mobility of the members of student associations very large, and also become a serious obstacle to the further development of student associations. The introduction of team management can complement each other's IQ and EQ in a certain extent. A group of students with different personalities, majors, personal abilities and interests can communicate with each other and exchange different views, solutions, knowledge, etc. and improve the speed and quality of solving difficult problems in the association.

\section{The value identity of the team-type association}

In the course of the development of the student associations, we must base on the students' standard, highlight the students' main body, take the students' internal needs as the logical starting point of the activities form, the management system and the operation mechanism of the associations, and insist on taking the students as the center. Whether it is beneficial to the development of students' personality and the promotion of students' comprehensive quality is regarded as the starting point and foothold of the development of the student associations. The student-based thought is transformed into the core motive force of the development of associations, which lays a theoretical foundation for the development of college associations[6].

Under the management mode of the team-type association, the students' association can combine the individual and the team closely through the activities of the association, thus forming the continuous motive force in the operation of the [7] association. The members of the association communicate with each other. Conflicts occur constantly in a team, and reconciliation continues to emerge behind the conflict. It is this interaction between individuals that makes it possible to form a valued identity within a good team. This value identity is an important pillar for the survival of the association, and it can adjust the cohesion ability of the team, the norm of system construction, the conflict between members, and so on. People who participate in student associations, through more concrete and practical community activities, let themselves deeply feel the collective, cooperate with each other and so on, so that members in the individual growth and the development of the entire association process can identify and cultivate collectivists. Under such circumstances, it is very useful to cultivate the collective consciousness of every member, and it can also greatly reduce the random or unstable behavior of the members of the association.

\section{CONCLUSION}

Under the current tide of deepening the comprehensive reform of higher education, the management mode of college system in universities is a hot issue that many universities are trying to practice and explore. Based on the college system, from the four dimensions construction of the goal identity, emotional identity, management identity and value identity of the student team society, we can give play to the vitality of the student association, and promote the combination of the general education and the professional education of the students.

\section{REFERENCES}

[1] Cui Yanqiang. Study on the evolution and modern value of the English residential college education [D].Chongqing: Southwest University, 2015

[2] He Yi, Research on University College System from the Perspective of Modern University System. China Social Science Publishing House, 1st Edition (June 1, 2017)

[3] Li Chunhua, Wei Junshuai. The promotion of the ideological and political education of college students in the new period. Neijiang Science \& Technology. No.7, PP.64, Jul. 2012

[4] Jia Xiangrui, Sun Chunyan, Bao Zuochen. Problems and solutions for student associations in medical higher education. China Higher Medical Education.No.3, pp, 9-10, Mar. 2015

[5] Liu Decai. Research On Cultivating Innovative and Entrepreneurship Talents in College System of Local Universities. China Adult Education. No.24, pp.67-69, Dec.2018

[6] Liu Fenglin. The present situation and measures of the development of college students' associations from the perspective of quality development. China Higher Education.No.23, pp.20-22, Dec. 2013 